\title{
WHAT ARE THE MOST IMPORTANT FIELD ZONES WHEN GOALPOSTS ARE MANIPULATED IN SOCCER?
}

original paper

(1) University School of Physical Education in Wroclaw

DOI: https://doi.org/10.5114/hm.2018.81015

\section{LUCAS OMETTO ${ }^{1,2}$, RODOLFO DE ALKMIM MOREIRA NUNES ${ }^{1}$, GIBSON MOREIRA PRACA ${ }^{3}$, FABRICIO VASCONCELLOS ${ }^{1,2}$}

${ }^{1}$ Postgraduate Program in Exercise and Sport Sciences, Rio de Janeiro State University, Rio de Janeiro, Brazil

${ }^{2}$ Laboratory of Studies in Soccer, Rio de Janeiro State University, Rio de Janeiro, Brazil

${ }^{3}$ Department of Physical Education, Federal University of Vales do Jequitinhonha e Mucuri, Diamantina, Brazil

\section{ABSTRACT}

Purpose. To compare the range and depth of ball circulation, the time of ball possession in each corridor and sector, and the zones of incidence of finalizations in small-sided and conditioned games (SSCG).

Methods. Overall, 27 under-15 soccer players performed 21 games, 7 games in each task condition (SSCGs with goalkeepers - SSCGG; without goalkeepers - SSCGWG; and with mini-goals - SSCGMG). The videos were analysed with the Soccer Analyser software. The range and depth of ball circulation were evaluated by the number of corridor variations (NCV) and the number of depth variations (NDV), respectively.

Results. In SSCGG and SSCGWG, there was a significant difference of the time in which the ball remained in each corridor. As for the number of finalizations in each field zone, SSCGG presented a significant difference in the central offensive zone with 42 finalizations; SSCGWG showed a higher number of finalizations in the defensive zones; and SSCGMG exhibited more finalizations in the right and left offensive zones. There was no significant difference in the NCV or NDV variables.

Conclusions. The manipulation of goalposts in SSCG was able to generate new behaviour patterns in the teams.

Key words: soccer training, small-sided and conditioned games, performance analysis, tactical behaviour, task constraints

\section{Introduction}

Currently, some teaching proposals in soccer are based on the idea of developing the teaching-learning process through a constant interaction between the player and the environment, in which tasks must be facilitated and/or hampered by the teacher/coach [1], aiming at the achievement of certain pedagogical purposes. These proposals produce learning contexts by exposing the athletes to game situations and, consequently, improving the tactical understanding of the game by the players [2,3]. One of the most applied means to develop the tactical understanding is the use of small-sided and conditioned games (SSCG), which are characterized by allowing changes in the size and shape of the field, number of players, and the rules of the game according to the intended objective $[4,5]$.
In addition, the teaching-learning process through SSCG allows the development of physical, technical, tactical, and psychological capacities in a contextualized way [6-8], bringing the teaching of soccer closer to the ecological dynamics perspective. In this way, the behaviour emerges from the dynamic interaction between each individual with the environment and the task $[2,4,9,10]$. Thus, changes in constraints may condition players' behaviour during SSCG; constraints can be classified into 3 types: (a) environmental constraints - playing on a dry or wet surface, under high or low temperatures, on natural or synthetic grass; (b) task constraints - number of players, field size, number of targets, rules, among others; and (c) individual constraints - technical and physical skills, chronological age and previous experience [11, 12].

The modifications in the task appear as constraints

Correspondence address: Fabrício Vieira do Amaral Vasconcellos, Rio de Janeiro State University, Rua São Francisco Xavier 524, Pavilhão João Lira Filho, $9^{\circ}$ andar, Bloco F, sala 9134, Maracanã, Rio de Janeiro, RJ, CEP: 20550-900, Brazil, e-mail: fabriciovav@gmail.com

Received: July 31, 2018

Accepted for publication: December 7, 2018

Citation: Ometto L, Nunes RAM, Praca GM, Vasconcellos F. What are the most important field zones when goalposts are manipulated in soccer? Hum Mov. 2018;19(5)special/issue:106-113 doi: https://doi.org/10.5114/hm.2018.81015. 
commonly adopted by coaches, especially with regard to the manipulation in the number and quantity of targets or goalposts $[4,5]$. According to Costa et al. [13], the manipulation of goalposts in SSCG can facilitate the understanding of tactical actions that occur outside the game centre. In this way, it can help the player in the comprehension of specific tactical aspects of the game. Although coaches constantly alter the goalposts, few studies have investigated the influence of the manipulation of this constraint on individual and/ or collective technical and tactical behaviours in soccer [7, 13-17]. In addition, no study has sought to identify the impact of the presence or absence of the goalkeeper in SSCG, since in addition to protecting the main objective of the game, the goalkeeper is also a player who assists both the defensive and the offensive phase. Thus, it is not known whether the presence of the goalkeeper directly influences the actions taken by the teammates and opponents.

In a study by Travassos et al. [17], senior professional players (mean age: 24.85 years) were evaluated; an increase in the number of targets meant that the ball remained longer in the lateral corridors and the defensive sector during SSCG, as well as the distance of the team centre in the defensive sector of the playing field was bigger. Similarly, Costa et al. [13] analysed tactical behaviours with the use of the System of Tactical Assessment in Soccer (FUT-SAT) $[18,19]$ among under-13 players and demonstrated that the decrease in target size increased the number of tactical behaviours of penetration, space, offensive unit, and concentration performed in SSCG. On the other hand, SerraOlivares et al. [15] manipulated the purpose of the game - goals with reduced goalposts vs. transposition of the opponent's bottom line - and did not observe significant differences in the solution of tactical problems using the Game Performance Evaluation Tool (GPET) in under-10 players (mean age: 8.7 years).

Owing to the inconsistency of the results observed in the previous studies, in addition to the fact that to date no study has sought to identify the influence of the presence of targets with and without goalkeepers in SSCG, it is necessary to understand how these factors may influence the development of soccer players' tactical knowledge and, subsequently, as suggested by Mackenzie and Cushion [20], seek to comprehend how and what athletes learn in these tasks by analysing the information that occurs in training.

According to recent studies [12,13], it is believed that the manipulation of goalposts may interfere in the zones of major importance and in the place where the ball will remain during SSCG. Broadening the knowledge about these factors can improve the train- ing capacity of coaches with regard to the specific purpose of the training session and to the strategy to be used for the next game [21].

It is also important to highlight that just a few studies that used SSCG as a method evaluated the participation of a goalkeeper in the game. Therefore, it is essential to determine the difference between SSCG with and without the presence of a goalkeeper, and thus identify the consequences of their presence in technical tactical actions. Evaluation methods should be created so that goalkeepers are also evaluated in future studies.

Therefore, the aim of this study was to compare the range and depth of ball circulation, the time of ball possession in each corridor and sector, and the zones of incidence of finalizations in SSCGs with goalkeepers (SSCGG), without goalkeepers (SSCGWG), and with mini-goals (SSCGMG) practiced by under-15 soccer athletes.

\section{Material and methods}

\section{Participants}

The 27 players selected for this research were part of the under- 15 category (age: $14.63 \pm 0.3$ years) of a first division soccer club in the city of Rio de Janeiro, Brazil. The analysis took place in 2016. The morphological and body composition characteristics were height $(169.58 \pm 7.5 \mathrm{~cm})$, body mass $(60.89 \pm 7.4 \mathrm{~kg})$, body mass index $\left(21.2 \pm 0.1 \mathrm{~kg} / \mathrm{m}^{2}\right)$, and fat percentage $(9.67 \pm 3.5 \%)$. The average length of stay in the club was $21.38 \pm 10.5$ months.

Included were athletes born in 2001 and training in a systematic manner for the preceding 6 months in a first division club. The exclusion criteria involved any injury or muscle discomfort, or recovering from an injury.

\section{Procedures}

During the course of the study, the players participated in 21 games, with 7 games in each condition (SSCGG, SSCGWG, and SSCGMG). The members of the technical committee composed the teams in a way to generate technically balanced confrontations. The match-fixing system took place from a simple elimination championship (quarterfinals, semi-final, and final), totalling 7 games for each condition, which was intended to increase the players' motivation.

All SSCGs were held on natural grass and lasted 4 minutes. The field size was $36 \times 27 \mathrm{~m}$, and all rules of soccer were followed except for the offside. No feedback was provided to the athletes during practice. The 


\section{HUMAN MOVEMENT}

L. Ometto, R.A.M. Nunes, G.M. Praca, F. Vasconcellos, The most important field zones in soccer

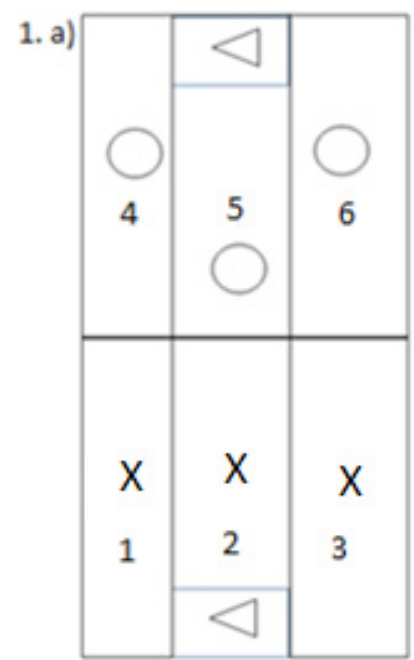

1. b)

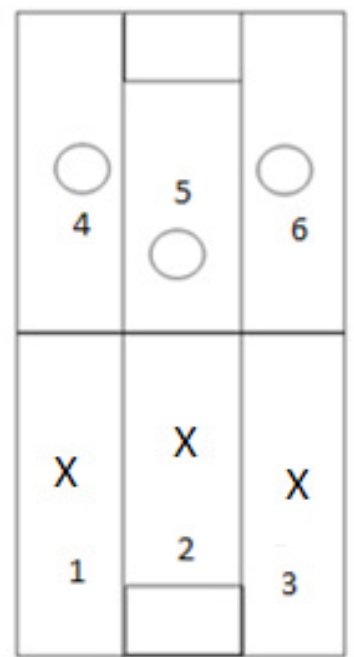

1. c)

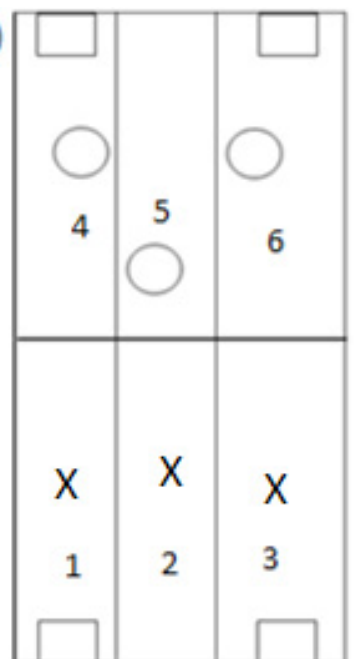

1 - left defensive zone, 2 - central defensive zone, 3 - right defensive zone, 4 - left offensive zone, 5 - central offensive zone, 6 - right offensive zone

Figure 1. Field zones of small-sided and conditioned games (a) with goalkeepers, (b) without goalkeepers, and (c) with mini-goals

SSCGs were preceded by a 15-minute warm-up lightweight run. Each SSCG was the only activity performed on the day and took place on different days with a 24-hour interval. In addition, there was an interval of $12 \mathrm{~min}$ utes between each elimination phase.

For the shooting of the games, a Sony HDR-CX220 camera was used. The videos were transported to a Lenovo computer, and the video was processed and analysed with the Soccer Analyser software. The software allows the insertion of spatial references in order to verify in which corridor/sector the ball was located and which zone was involved in the finalization [19, 22]. To identify the time in which the ball stayed in each zone of the field, a Timex T5K 491Sr/Ti chronometer was used. The count started from the moment when the ball entered the corridor (left, centre, and right) and sector (defensive and offensive). The final time included only the moments when the ball was in play. The moments with the ball out of play (sides, faults, and goal kicks) were not counted.

The analysis of the finalizations referred to each zone of the field (left defensive zone, central defensive zone, right defensive zone, left offensive zone, central offensive zone, and right offensive zone).

In order to evaluate the range of the ball circulation in the game, the variable number of corridor variations (NCV) was used, which refers to the number of times the ball circulates from one corridor to the other, either by passing or driving. To analyse the depth, we verified the number of times the team circulated the ball by passing or driving from the defensive midfield to the offensive midfield, resulting in the number of depth variations (NDV) [23].
Constraints in the small-sided and conditioned games

The SSCGs were performed under 3 different conditions. Figure 1 a represents the structure of $G+3 \times$ $3+\mathrm{G}$, goals of $6 \times 2 \mathrm{~m}$. Figure $1 \mathrm{~b}$ shows the SSCGWG, in which the structure of $3 \times 3$ was maintained, goals of $6 \times 2 \mathrm{~m}$, but without the presence of goalkeepers. Figure 1c depicts the SSCGMG, in which the $3 \times 3$ structure was maintained, with two mini-goals of $1.80 \times 0.60 \mathrm{~m}$ located at the bottom line, close to the laterals, and without the presence of goalkeepers.

\section{Statistical analysis}

The data were analysed with the SPSS v. 24.0 software (SPSS Inc., Chicago, IL, USA) and presented as means, standard deviations, and percentages. To verify the normality of the data, the Kolmogorov-Smirnov test was applied. For the comparison of the time in each corridor and sector and for the number of finalizations in each field zone, besides the NCV and the NDV, the repeated measures ANOVA was used, followed by Bonferroni post hoc, after confirming the assumptions of homoscedasticity of variances and sphericity. In the results that presented significant differences, the effect size test $\left(\eta^{2}\right)$ was also used, with the following interpretation: small effect: $0.02 \leqslant \eta^{2}<0.13$; medium effect: $0.13 \leq \eta^{2}<0.26$; large effect: $\eta^{2} \geq 0.26$ [24]. The study adopted the value of $p<0.05$ for statistical significance. 


\section{Ethical approval}

The research related to human use has been complied with all the relevant national regulations and institutional policies, has followed the tenets of the Declaration of Helsinki, and has been approved by the National Health Council of Brazil and the Research Ethics Committee of Pedro Ernesto University Hospital at the Rio de Janeiro State University (HUPE/ UERJ); the study has been registered under the number 52519815.4.0000.5259.

\section{Informed consent}

Informed consent has been obtained from the legal guardians of all individuals included in this study.

\section{Results}

Table 1 shows the mean and standard deviation of the time (in percentages and absolute values) in which the ball remained in each corridor and sector during the SSCGs, and a comparison between each SSCG. Among the SSCGs, a significant difference was observed in the following variables: the SSCGWG and the SSCGG caused the ball to remain longer in the central corridor $\left(\eta^{2}=0.5 ; p<0.05\right.$; small effect) as compared with SSCGMG. When comparing the time the ball remained in each corridor and sector in the same SSCG, we found that in the SSCGG and the SSCGWG, the ball remained longer in the centre corridor than in the left corridor $\left(\eta^{2}=0.2 ; p<0.05\right.$; medium effect) and right corridor $\left(\eta^{2}=0.03 ; p<0.05\right.$; small effect), while in the SSCGMG there was no significant difference between the time in the corridors. For the defensive $\left(\eta^{2}=0.2 ; p<0.05\right.$; medium effect $)$ and offensive $\left(\eta^{2}=0.3 ; p<0.05\right.$; large effect) sectors, in all SSCGs, the ball remained longer in the defensive sector than in the offensive one.

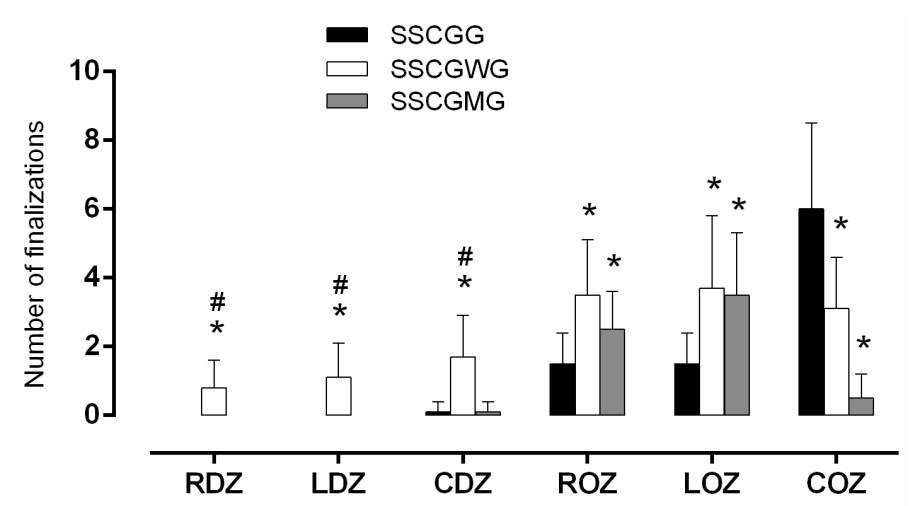

RDZ - right defensive zone, LDZ - left defensive zone; CDZ - central defensive zone, ROZ - right offensive zone, LOZ - left offensive zone,

$\mathrm{COZ}$ - central offensive zone

\# significant difference for 2 mini-goals $(p<0.05)$

* significant difference for the small-sided and conditioned game $(p<0.05)$

Figure 2. Total number of finalizations, mean and standard deviation in each field zone of each small-sided and conditioned game

In relation to the number of finalizations in each field zone of each SSCG, a significant difference was found (Figure 2) in the number of finalizations in the central offensive zone $\left(\eta^{2}=0.6 ; p<0.05\right.$; large effect) of the SSCGG as compared with the other 2 conditions. On the other hand, the SSCGWG and the SSCGMG showed a significant difference in the number of finalizations in the right offensive zone $\left(\eta^{2}=0.3 ; p<\right.$ 0.05 ; large effect $)$ and in the left offensive zone $\left(\eta^{2}=0.3\right.$; $p<0.05$; large effect) as compared with the SSCGG. In the defensive zones, the SSCGWG presented a significant difference in the number of finalizations in all defensive zones (right: $\eta^{2}=0.4$; central: $\eta^{2}=0.5$; left: $\eta^{2}=0.5 ; p<0.05$; large effect) as compared with the other 2 game conditions.

As can be observed in Table 2, for the NCV and NDV variables, no significant difference was found between the SSCGs ( $p=0.29$ and $\eta^{2}=0.09 ; p=0.06$ and $\eta^{2}=0.36$ ).

Table 1. Mean and standard deviation of the time, in percentages (\%) and absolute values (seconds), in which the ball stayed in each corridor and sector during the SSCGs, and a comparison between each SSCG

\begin{tabular}{lccc}
\cline { 2 - 4 } & SSCGG & SSCGWG & SSCGMG \\
\hline Right corridor & $26^{\mathrm{b}}(302 \pm 13.3)$ & $28 \%^{\mathrm{b}}(293 \pm 13.6)$ & $32 \%(328 \pm 7.2)$ \\
Central corridor & $46^{*}(525 \pm 16.3)$ & $45 \%^{*}(474 \pm 14.1)$ & $29 \%^{*}(294 \pm 9.3)$ \\
Left corridor & $28 \%^{\mathrm{b}}(325 \pm 11.7)$ & $27 \%^{* \mathrm{~b}}(284 \pm 12.7)$ & $39 \%^{\mathrm{b}}(390 \pm 7.6)$ \\
Defensive sector & $67 \%^{\mathrm{a}}(867 \pm 19.2)$ & $71 \%^{\mathrm{a}}(812 \pm 10.0)$ & $65 \%^{\mathrm{a}}(762 \pm 15.5)$ \\
Offensive sector & $33 \%(435 \pm 8.8)$ & $29 \%(335 \pm 9.9)$ & $35 \%(402 \pm 12.7)$ \\
\hline
\end{tabular}

SSCGG - small-sided and conditioned games with goalkeepers, SSCGWG - small-sided and conditioned games without goalkeepers, SSCGMG - small-sided and conditioned games with mini-goals

\# significant difference $(p<0.05)$ for the two mini-goals

* significant difference $(p<0.05)$ for the small-sided game

a significant difference $(p<0.05)$ for the offensive sector

${ }^{\mathrm{b}}$ significant difference $(p<0.05)$ for the central corridor 
L. Ometto, R.A.M. Nunes, G.M. Praca, F. Vasconcellos, The most important field zones in soccer

Table 2. Means and standard deviations of the NCV and NDV variables in each small-sided and conditioned game, and the $p$ value and the effect size

\begin{tabular}{lccccc} 
& SSCGG & SSCGWG & SSCGMG & $p$ & Effect size \\
\cline { 2 - 6 } $\mathrm{NCV} / \mathrm{min}$ & $14.7(3.85)$ & $14.4(3.08)$ & $13.1(3.10)$ & 0.29 & 0.09 \\
$\mathrm{NDV} / \mathrm{min}$ & $4.9(1.99)$ & $6.4(2.15)$ & $4.5(1.53)$ & 0.06 & 0.36 \\
\hline
\end{tabular}

SSCGG - small-sided and conditioned games with goalkeepers, SSCGWG - small-sided and conditioned games without goalkeepers, SSCGMG - small-sided and conditioned games with mini-goals, NCV - number of corridor variations, $\mathrm{NDV}$ - number of depth variations

\section{Discussion}

The aim of the present study was to compare the range and depth of ball circulation, the time of ball possession in each corridor, and the zones of incidence of finalizations in SSCGG, SSCGWG, and SSCGMG practiced by under-15 soccer athletes. As the main results, it can be seen that in the SSCGMG, the ball stayed longer in the lateral corridors, while in the other conditions (SSCGG and SSCGWG), the ball remained longer in the central corridor of the field. In addition, there was a significant difference between the SSCGs as for the field zones in which the finalizations occurred; the SSCGG showed more finalizations in the central offensive corridor, the SSCGWG had more finalizations from the defensive field, and the SSCGMG presented a greater number of finalizations in the lateral zones of the game offensive field.

Regarding the quantity and location of the finalizations in each SSCG, it was evidenced that the manipulation of the goalposts and the lack or presence of the goalkeeper interfered in the number and zones of finalization. The SSCGWG induced players to finish more, including the defensive sector, since the target was large and easy to hit, and a short space was needed between the attacker and the defender to create the finishing angle. The SSCGMG, owing to the reduced dimensions of the goalposts, presented a smaller number of finalizations, and the zones with the highest number of finalizations were closely related to the zones near the mini-goals (left and right offensive zones). Meanwhile, the SSCG with a central goal and goalkeeper generated a greater number of finalizations in the central offensive zone.

Vilar et al. [25] had similar objectives as those in the present study with regard to the finalizations. The authors evaluated the distance between attackers and defenders, and the angle of each player to the ball and the goal. The study found that goals in official futsal matches tended to occur when the attackers' angle to goal and defender increased. In this way, increasing or decreasing the angle between the ball and the goalposts in relation to the defensive position of the team is a key point to protect the goal and not allow the creation of finishing situations [25, 26]. These findings are in agreement with some studies demonstrating that goalposts manipulations (quantity, size, and location) promote informational changes in SSCG, giving players new possibilities of finalizations in different areas of the field [14, 27]. In addition, this fact may have a consequence in technical-tactical learning, such as improving long-distance finalization and increasing pressure on the player with the ball so that finalization does not occur.

Although it was carried out with goalposts of different sizes, the study by Clemente et al. [14] used different formats $(2 \times 2,3 \times 3$, and $4 \times 4)$ for a small group of amateur and adult (mean age: $26.4 \pm 5.3$ years) soccer players. Their findings are in line with those of the present study in relation to the greater number of finalizations. In SSCG with a larger goalpost (beyond the baseline), a greater number of passes and finalizations were found than in SSCG with smaller goalposts (finalization in a mini-goal and in 2 minigoals). A similar result was obtained in the present study, in which there was a greater number of finalizations in the SSCGG (larger goalpost). Although the athletes' age and technical level are different, the manipulation of task constraints had a great impact on the results of tactical and technical aspects.

Another study [24] with U-17 soccer players analysed the number of goals and the time the ball remained in each corridor in SSCG with a mini-goal and 3 mini-goals. It turned out that there were 2 times more finalizations with 3 mini-goals $(2.2 \pm 0.5)$ than in the SSCG with a mini-goal $(1.0 \pm 0.8)$, showing that the greater facility in accomplishing the finalization increased the number of finalizations in the SSCG with a bigger number of goalposts. This may enhance a youth team learning of this technical-tactical action and understanding of specific tactical aspects of the game, such as pressing the player with the ball, with greater proximity or distance of the defensive coverage in relation to the player with the ball. 
The manipulation of goalposts requires new adaptation of the players with respect to the field zones that will be used to explore actions during the game $[6,21]$. Although there was no significant difference as compared with the time the ball remained in the lateral corridors, a significant difference was found for the SSCGMG, in which the ball stayed less time in the central corridor than with the other 2 conditions (SSCGG and SSCGWG). In this way, there was greater use of the lateral corridors with 2 mini-goals. This result corroborates the findings of Travassos et al. [7], regarding professional football players (mean age: $24.85 \pm 4.1$ years). The rise in the number of targets from 2 to 6 , increased the time of the ball in the lateral corridors from $41 \%$ (2 targets) to $58.9 \%$ (6 targets).

However, Figueiredo et al. [27] observed no difference between SSCG with 1 target and SSCG with 3 targets in relation to the time the ball remained in each corridor. The authors believe that the higher number of targets generated a greater risk of loss of ball possession, promoting more caution among players and, consequently, reducing the number of passes between them. In this way, the use of more targets can increase the search of the players in the lateral corridors to reach the goal, and may be an alternative to potentiate certain specific tactical game behaviours in accordance with the coach's tactical proposal.

As for the time of ball possession in the sectors of the field, no difference was found between the 3 conditions, which is in agreement with the observations of Travassos et al. [7]. In this study, it was shown that in the $5 \times 5$ with a size of $30 \times 25 \mathrm{~m}$, the ball remained longer in the defensive sector when a greater number of goalposts were used. Therefore, the increase in the number of goalposts, the reduced number of players $(3 \times 3)$, and the larger size of the field $(36 \times 27 \mathrm{~m})$ may have provided more playing space, increasing the possibilities of finalization and causing the players to seek the goal with greater speed. This fact made the team, when entering in the defensive sector, to reduce the spaces, seeking to recover the possession of ball in the offensive sector. The aim was to hinder the progression, which made the game more dynamic and made offensive and defensive transitions faster. In this way, the ball remained the same time in both the defensive and offensive sectors.

Although the present study found a longer time in the lateral corridors in the SSCGMG, this did not result in a greater amplitude of the circulation of the ball possession, probably because the players tried to score on the same side that started the possession of the ball. This result suggests that the age of the players in the study had a great influence on the behaviour in the SSCG, since research indicates that players with greater experience tend to present different tactical responses to complex game situations [28-30].

A limitation of the study that can be pointed out is the selection of players from each team, which was carried out by the technical committee members. Another limitation can be that the sample represented only one soccer club. Therefore, any comparison of the obtained results with other studies requires caution, and the outcomes cannot be generalized for all ages. Despite the relevance of the variables evaluated in the present study, it is also important to add more variables in future research based on the specific characteristics needed by soccer players during a match.

\section{Conclusions}

The manipulation of goalposts in the SSCG was able to generate new behavioural patterns in the teams in the exploration of the field corridors to obtain the objective, as for the zones in which most of the finalizations took place. The SSCGG and the SSCGWG made the ball stay longer in the central corridor, while the increase in the number of goalposts from one to two resulted in the ball staying less time in the central corridor, which made the players to explore for longer the lateral corridors. Moreover, the greater facility to score, due to the goalkeeper's absence and the increase in the number of goalposts, caused more finalizations in areas further away from the target.

Thus, from a practical point of view, although the ages are different in several studies and the experience of each player is of extreme importance for learning, the tasks chosen by the trainer for training are capable of generating tactical behavioural patterns that he seeks. If the coach wants to explore the achievement of specific tactical objectives in the training session, i.e. to play on the laterals of the field and to reduce the spaces for the opponent, it seems that the goalposts may be one of the constraints manipulated. Additionally, the lack or presence of the goalkeeper can directly influence the behaviour of the players in the defensive zone, i.e. having to press the ball carrier with more speed, since the presence or absence of the goalkeeper can facilitate or hamper the achievement of the game purpose. Therefore, considering that the target represents the primary goal, in addition to being a constraint constantly manipulated by coaches in their training sessions, the investigation of this specific constraint and the changes induced in the tactical behaviour of players from its manipulation should continue to guide future studies because of its importance. 
L. Ometto, R.A.M. Nunes, G.M. Praca, F. Vasconcellos, The most important field zones in soccer

\section{Disclosure statement}

No author has any financial interest or received any financial benefit from this research.

\section{Conflict of interest}

The authors state no conflict of interest.

\section{References}

1. Clemente FM. Pedagogical principles of teaching games for understanding and nonlinear pedagogy in the physical education teaching [in Portuguese]. Movimento. 2012; 18(2):315-335; doi: 10.22456/1982-8918.27495.

2. Chow JY, Davids K, Button C, Shuttleworth R, Renshaw I, Araujo D. Nonlinear pedagogy: a constraintsled framework for understanding emergence of game play and movement skills. Nonlinear Dynamics Psychol Life Sci. 2006;10(1):71-103.

3. Renshaw I, Chow JY, Davids K, Hammond J. A constraints-led perspective to understanding skill acquisition and game play: a basis for integration of motor learning theory and physical education praxis? Phys Educ Sport Pedagogy. 2010;15(2):117-137; doi: 10.1080/ 17408980902791586.

4. Davids K, Araújo D, Correia V, Vilar L. How small-sided and conditioned games enhance acquisition of movement and decision-making skills. Exerc Sport Sci Rev. 2013; 41(3):154-161; doi: 10.1097/JES.0b013e318292f3ec.

5. Ometto L, Vasconcellos FVA, Cunha FA, Teoldo I, Souza CRB, Dutra MB, et al. How manipulating task constraints in small-sided and conditioned games shapes emergence of individual and collective tactical behaviours in football: a systematic review. Int J Sports Sci Coach. 2018;13(6):1200-1214; doi: 10.1177/1747954 118769183.

6. Hill-Haas SV, Rowsell GJ, Dawson BT, Coutts AJ. Acute physiological responses and time-motion characteristics of two small-sided training regimes in youth soccer players. J Strength Cond Res. 2009;23(1):111115; doi: 10.1519/JSC.0b013e31818efc1a.

7. Travassos B, Gonçalves B, Marcelino R, Monteiro R, Sampaio J. How perceiving additional targets modifies teams' tactical behavior during football small-sided games. Hum Mov Sci. 2014;38:241-250; doi: 10.1016/ j.humov.2014.10.005.

8. López LMG, Jordán ORC, Penney D, Chandler T. The role of transfer in games teaching: implications for the development of the sports curriculum. Eur Phy Educ Rev. 2009;15(1):47-63; doi: 0.1177/1356336X09105211.

9. Brymer E, Davids K. Experiential learning as a constraint-led process: an ecological dynamics perspective. J Adventure Educ Outdoor Learn. 2014;14(2):103-117; doi: 10.1080/14729679.2013.789353.

10. Vilar L, Araújo D, Davids K, Travassos B. Constraints on competitive performance of attacker-defender dyads in team sports. J Sports Sci. 2012;30(5):459-469; doi: 10.1080/02640414.2011.627942.
11. Vilar L, Araújo D, Davids K, Button C. The role of ecological dynamics in analysing performance in team sports. Sports Med. 2012;42(1):1-10; doi: 10.2165/ 11596520-000000000-00000.

12. Brymer E, Davids K. Ecological dynamics as a theoretical framework for development of sustainable behaviours towards the environment. Environ Educ Res. 2013; 19(1):45-63; doi: 10.1080/13504622.2012.677416.

13. Costa I, Garganta J, Greco P, Mesquita I, Silva B, Müller E, et al. Analysis of tactical behaviours in small-sided soccer games: comparative study between goalposts of society soccer and futsal. Open Sports Sci J. 2010;3(1): 10-12; doi: 10.2174/1875399X01003010010.

14. Clemente FM, Wong DP, Martins FML, Mendes RS. Acute effects of the number of players and scoring method on physiological, physical, and technical performance in small-sided soccer games. Res Sports Med. 2014; 22(4):380-397; doi: 10.1080/15438627.2014.951761.

15. Serra-Olivares J, González-Víllora S, García-López LM, Araújo D. Game-based approaches' pedagogical principles: exploring task constraints in youth soccer. J Hum Kinet. 2015;46(1):251-261; doi: 10.1515/hukin-20150053.

16. Silva P, Travassos B, Vilar L, Aguiar P, Davids K, Araújo D, et al. Numerical relations and skill level constrain co-adaptive behaviors of agents in sports teams. PLoS One. 2014;9(9):e107112; doi: 10.1371/journal. pone.0107112.

17. Travassos B, Coutinho D, Gonçalves B, Pedroso P, Sampaio J. Effects of manipulating the number of targets in U9, U11, U15 and U17 futsal players' tactical behaviour. Hum Mov Sci. 2018;61:19-26; doi: 10.1016/j.humov.2018.06.017.

18. Costa IT, Garganta J, Greco PJ, Mesquita I. Proposal for tactical assessment of soccer player's behaviour, regarding core principles of the game [in Portuguese]. Motriz: Rev Educ Fis. 2011;17(3):511-524; doi: 10.1590/S198065742011000300014.

19. Costa IT, Garganta J, Greco PJ, Mesquita I, Maia J. System of Tactical Assessment in Soccer (FUT-SAT): development and preliminary validation. Motricidade. 2011;7(1):69-83; doi: 10.6063/motricidade.7(1).121.

20. Mackenzie R, Cushion C. Performance analysis in football: a critical review and implications for future research. J Sports Sci. 2013;31(6):639-676; doi: 10.1080/02640 414.2012.746720.

21. Sarmento H, Clemente FM, Araújo D, Davids K, McRobert A, Figueiredo A. What performance analysts need to know about research trends in association football (2012-2016): a systematic review. Sports Med. 2018; 48(4):799-836; doi: 10.1007/s40279-017-0836-6.

22. Costa IT, Garganta J, Greco P, Mesquita I. Evaluation of tactical performance in soccer: conception and development of framework of tactical behavior analysis of "GK3-3GK” test [in Portuguese]. R Min Educ Fis. 2009;17(2):36-64.

23. Garganta J. Tactical modelling of the football game: 
a study of the organization of the offensive phase in teams of high performance [in Portuguese]. Doctoral dissertation. Porto: Porto University; 1997.

24. Pierce CA, Block RA, Aguinis H. Cautionary note on reporting eta-squared values from multifactor $\mathrm{ANO}$ VA designs. Educ Psychol Meas. 2004;64(6):916-924; doi: 10.1177/0013164404264848.

25. Vilar L, Araújo D, Davids K, Travassos B, Duarte R, Parreira J. Interpersonal coordination tendencies supporting the creation/prevention of goal scoring opportunities in futsal. Eur J Sport Sci. 2014;14(1):28-35; doi: 10.1080/17461391.2012.725103.

26. Travassos B, Araújo D, Duarte R, McGarry T. Spatiotemporal coordination behaviors in futsal (indoor football) are guided by informational game constraints. Hum Mov Sci. 2012;31(4):932-945; doi: 10.1016/j.humov. 2011.10.004.

27. Figueiredo DH, Figueiredo DH, Rodrigues AB, de Oliveira Matta M. Analysis of targets settings changes in the tactical behavior in a smaller and conditioned field [in Portuguese]. Rev Bras Futsal Futebol. 2016;8(28):77-82.

28. Giacomini DS, Silva EG, Greco PJ. Declarative tactical knowledge in soccer: a comparison study between soccer players of different categories and positions. Rev Bras Cienc Esporte. 2011;33(2):445-463; doi: 10.1590/ S0101-32892011000200011.

29. Costa BRS, de Almeida RF, da Costa IT. Comparative study of tactical behavior performed by under-13 and under-15 players. Rev Educ Fis. 2015;26(4):557-566; doi: 10.4025/reveducfis.v26i4.26830.

30. Olthof SB, Frencken WG, Lemmink KA. The older, the wider: on-field tactical behavior of elite-standard youth soccer players in small-sided games. Hum Mov Sci. 2015;41:92-102; doi: 10.1016/j.humov.2015.02.004. 